\title{
Physiological responses and effective selection criteria of drought tolerant plants
}

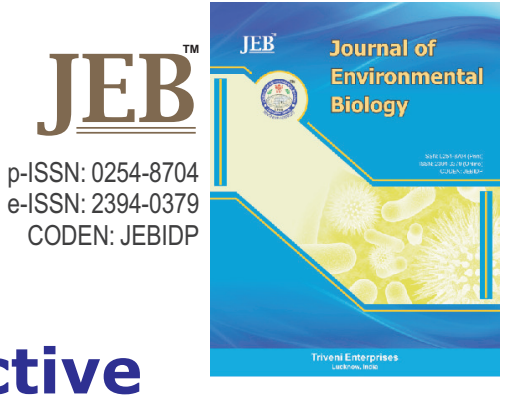

Authors Info

D.J. Park', H.J. $\mathrm{Im}^{3}$, H.G. Kim², W.H. Yang', S.H. Yong ${ }^{2}$ and M. S. Choi ${ }^{12 *}$

IInstitute of Agriculture and Life Science, Gyeongsang National University, Jinju 52828, The Republic of Korea

${ }^{2}$ Division of Environmental Forest Science, Gyeongsang National University, Jinju 52828, The Republic of Korea

${ }^{3}$ Plant Propagation and Reproduction Division, Baekdudaegan National Arboretum, Bonghwa 36209, The Republic of Korea

*Corresponding Author Email : mschoi@gnu.ac.kr

Key words

Drought tolerant plants Metabolites monitoring Physiological assessment Screening method Withering rates

\section{Publication Info}

Paper received : 08.12.2016 Revised received : 10.07.2017 Re-revised received : 28.12 .2017 Accepted : 30.12 .2017

\section{Abstract}

Aim : The present study was carried out to establish the method for screening drought tolerant Korean native plants and to analyze the appearances of drought tolerant Korean native plants on drought stress.

Methodology : Twelve Korean native plant species (Scilla scilloides, Commelina communis, Hemerocallis fulva, Bupleurum latissimum, Hosta plantaginea, Iris dichotoma, Lysimachia barystachys, Viola mandshurica, Amphicarpaea bracteata, Aeschynomene indica, Dianthus chinensis and Urtica thunbergiana), which were 16-week-old seedlings, were exposed to drought stress by stopping irrigation to observe phenotypic, physiological and biochemical responses.

Results : Based on the withering rates under drought condition, the plants were classified into three groups; drought tolerant (S. scilloides, C. communis, $H$. fulva, B. latissimum, $H$. plantaginea and $I$. dichotoma), normal (L. barystachys, V. mandshurica and A. bracteata) and sensitive (A. indica, $D$. chinensis and $U$. thunbergiana) group. While chlorophyll contents of the plants were generally decreased in the drought condition, the extents of decrement in the sensitive group were larger than in the tolerant group. RWCs in the tolerant group were higher than in the other groups on the same periods of drought condition. Proline and soluble reducing sugars accumulated in the sensitive group much earlier than in the tolerant group.

Interpretation : The results revealed that $S$. scilloides, C. communis, $H$. fulva, B. latissimum, $H$. plantaginea and $I$. dichotoma were screened as drought tolerant plants and the established method in the study can be applied to screen drought tolerant plants for Korean natives.

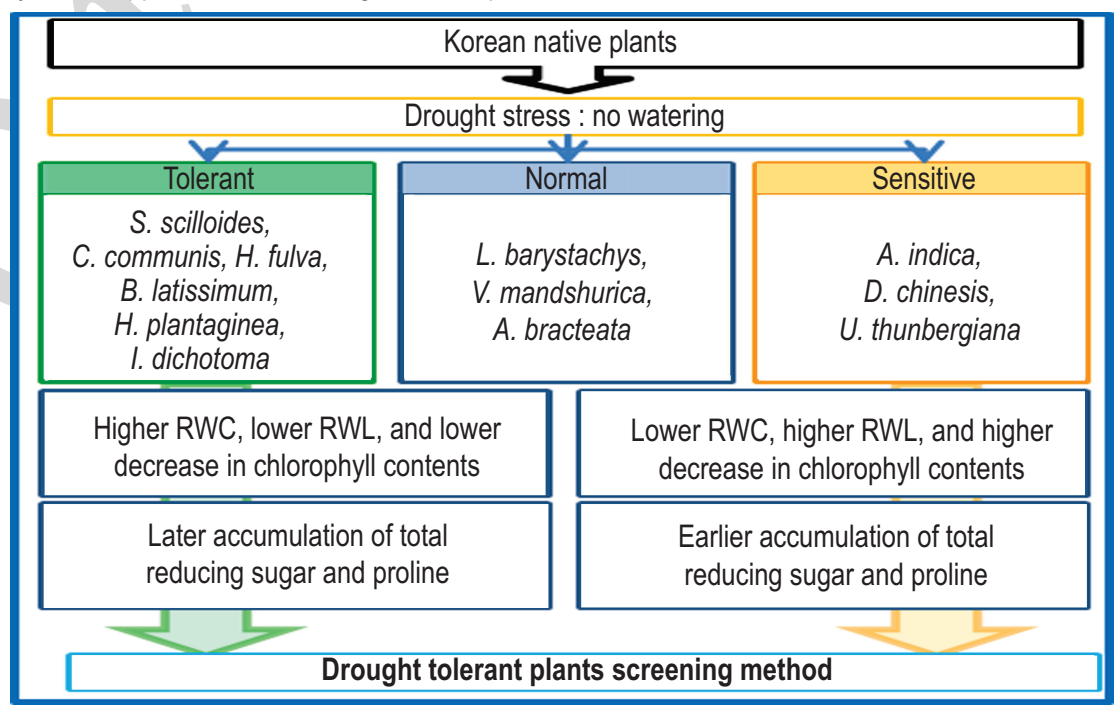




\section{Introduction}

Climate changes caused by global warming often provide forest plants with serious drought condition. Rises in temperature increase water loss by evaporation from soils (Helfer et al., 2012). In a previous study, each $1^{\circ} \mathrm{C}$ increase in soil temperature increased evaporation rate up to 10\% (Kidron and Kronenfeld, 2016). Moreover, changes in rainfall mainly cause drought conditions. Decrease in rainfall is the main cause of drought condition in specific areas. La Nina and El Nino, for example, have been indicated as the reasons of drought in North America and East China, where rainfall has reduced (Dai, 2011). Heavy rains also function for triggering floods and landslides. And then these natural disasters cause drought conditions by removing vegetation. These effects of climate change devastate the earth and accelerate desertification.

In South Korea, areas of devastated lands in forests for developments have increased (Woo and Jeon, 2005; Yim et al., 1999). Landslides are one of the main cause of devastated lands. The areas of landslides in South Korea has increased up to 713 ha in the 2000s from 289 ha in 1970s (Korea Forest Service, 2016). In addition, it has been suggested that land development in South Korea has increased devastated lands in the forest (Kim et al., 2013; Park et al., 2015). Therefore, efficient methods for recovering devastated lands are required (Sim and Kim, 2006). Methods using plants has been suggested to recover devastated lands (Kim et al., 2008; Jeon, 2002). Because of extreme environmental conditions in the devastated lands, the use of environmental stress tolerant plants have been suggested (Atif, 1988). Some introduced plant species such as weeping lovegrass, rudbeckia and tall fescue are usually used for recovering the devastated lands (Kil et al., 2011; Park et al., 2009). However, it is concerned that using few number of plants species inhibits biodiversity. Therefore, various drought tolerant native plants are demanded. Nevertheless, suitable plant species have not been reported even though the devastated lands constrain drought condition.

Most plants undergo water deficiency when supplying water to root system is inhibited or when transpiration in the plants is actively carried out. Several studies have reported plants' physiological and metabolic response to drought stress. Physiological parameters such as relative water content, chlorophyll content have been used as key indicators of drought stress (Soltys-Kalina et al., 2016; Ganji Arjenaki et al., 2012; Mafakheri et al., 2010; Arunyanark et al., 2008). Furthermore, for observing metabolic responses to drought stress, proline and total reducing sugar contents are determined (Wu et al., 2014; Naser et al., 2010). However, these studies were conducted mainly based on model plants and crops.

Drought tolerant plants refer to plants having high adaptability to drought stress, which is considered as an important trait for crops productivity. Several studies have been carried out to screen drought tolerant rice (Kumar et al., 2014;
Sakai et al., 2010; Barba Jr. et al., 2014) and cotton (Longenberger et al., 2006; Ullah et al., 2017). Korean native drought plants need to be screened and planted in forests to enhance the adaptability of forests against climate change and efficiency for recovering devastated lands. In the view of above study was carried out to establish a method for screening Korean native drought tolerant plants and to observe their responses to drought stress.

\section{Materials and Methods}

Plant materials and drought stress treatment : To test tolerance to drought stress, twelve Korean native plant species were collected from Gyeongsangnam-do Forest Environment Research Institute in Jinju, Korea (Table 1). All plant species were reconfirmed by using the Korean plant name index (Lee, 2003), and Nature system on Korean National Arboretum (www.nature.go.kr). Collected plants were stabilized grown in a greenhouse in Gyeongsang National University for 30 days. Plant species which showed a similar growth were then selected to avoid experimental errors and used for further experiments. Before the Korean native plants were exposed to drought condition, their growth features such shoot length, leaf number, leaf width and leaf length and thickness were measured (Table 1). The withering rates, as phenotypic response of the plants, were observed for 60 days under drought condition, which was initiated by stopping irrigation.

Chlorophyll content : The chlorophyll content in the leaf of explant was determined with a chlorophyll meter (SPAD-502, Spectrum Technologies Plainfield, IL). Five sample leaves of each species grown in drought condition were measured. The chlorophyll contents were measured at midday (11:00 - 13:30 hr) at a 6 day interval for 4 weeks.

Relative water content and relative water loss : Relative water content (RWC) was determined according to the method of Turner et al. (1986). Fresh leaves were weighed immediately to record fresh weight (f.wt.). They were then placed in distilled water for $4 \mathrm{hrs}$ and weighed again to record turgid weight (TW). After that, they were subjected to dry oven at $70^{\circ} \mathrm{C}$ for 24 hrs to record dry weight (d.wt.). Relative water loss (RWL) was measured as follows : The leaf samples were weighed, wilted for $4 \mathrm{hrs}$ at $35^{\circ} \mathrm{C}$, reweighed (W $4 \mathrm{hr}$ ) and oven dried for $24 \mathrm{hrs}$ at $72^{\circ} \mathrm{C}$ to obtain dry weight. The RWC and RWL were measured at 6 days interval for 3 weeks and calculated by the following formula :

$$
\begin{aligned}
\operatorname{RWC}(\%) & =[(\mathrm{FW}-\mathrm{DW}) /(\mathrm{TW}-\mathrm{DW})] \times 100 \% \cdots \cdots \cdots \cdots(1) \\
\operatorname{RWL}(\%) & =[(\mathrm{FM}-\mathrm{W} 4 \mathrm{hr}) /(\mathrm{FW}-\mathrm{DW})] \times 100 \% \cdots \cdots \cdots \cdots \cdots(2)
\end{aligned}
$$

Proline contents analysis : Proline was determined as described by Bates et al. (1973). Fresh leaf tissues $(0.05 \mathrm{~g}$ ) were extracted mixed with $5 \mathrm{ml}$ aqueous sulfosalicylic acid $(3 \% \mathrm{w} / \mathrm{v})$. The extracted solution was reacted with an equal volume of glacial acetic acid and ninhydrin reagent and incubated at $100^{\circ} \mathrm{C}$ for one hr. The reaction mixture was vigorously mixed with $2 \mathrm{ml}$ toluene in an ice bath. The chromophore was measured with a spectrophotometer DR/4000 at $520 \mathrm{~nm}$. The concentration of 
proline was calculated from a calibration curve plotted with known concentration of proline as standard.

Estimation of soluble reducing sugar : The soluble reducing sugar was estimated following the DNS (3,5-Dinitrosalicylic acid) method of Miller (1972). Fresh leaf tissues $(0.1 \mathrm{~g})$ were extracted in $5 \mathrm{ml}$ distilled water at $100^{\circ} \mathrm{C}$ for $30 \mathrm{~min}$. The extracted solution reacted with $1.0 \mathrm{ml}$ DNS (3.5-Dinitrosalicylic acid) were mixed and then treated in boiling water for $5 \mathrm{~min}$ and the absorbance was measured with a spectrometer DR/4000 at $546 \mathrm{~nm}$. Various concentration $\left(50,100,150\right.$ and $\left.200 \mu \mathrm{g} \mathrm{ml}^{-1}\right)$ of glucose was measured for calibration curve with " $Y=0.2643 x-0.254$ $\left(R^{2}=0.9893\right)$ ".

Statistical analysis : The growth characteristics and chlorophyll content, RWCs, RWLs, proline content, sugar content and the mortality for the twelve plant species were analyzed for significance by one-way ANOVA using the IBM SPSS statistical package and the Duncan multiple range test (Table 1, 2). The correlations among physiological and biochemical factors related to drought tolerance were determined by regression analysis. All of the statistical analysis conducted under 0.05 of significance level.

\section{Results and Discussion}

The phenotypic response of each plant material under non-irrigation condition for 60 days was observed to establish the method for screening native Korean drought tolerant plants. The withering rates of each plant species were differently shown although they all increased with duration (Fig. 1). After monitoring them, twelve Korean native plants were divided into three groups: tolerant group, normal group and sensitive group. The tolerant group refers to plant species showing low withering rate than $50 \%$ in 30 days with no watering. In the tolerant group, S. scilloides, C. communis, $H$. fulva, $H$. plantaginea and $I$. dichotoma were included. The normal group, which showed lower withering rates than $50 \%$ in 20 days under drought condition included $L$. barystachys, V. mandshurica and $A$. bracteata. Three plant species ( $A$. indica, $D$ chinensis and $U$. thunbergiana) in the sensitive group showed higher withering rate than $50 \%$ in 20 days. These significant differences in phenotypic response under drought stress suggests that tolerant abilities of Korean native plants vary. Similar results were obtained in the research that 'Katahdin', a drought tolerant genotype of potato, showed higher yields than others under drought condition by stopping watering (Soltys-Kalina et al., 2016). Therefore, the method to treat drought by stopping watering can be used to screen drought tolerant plants. Continuously, it was required to investigate which physiological and metabolic features are shown in the plants of each group at following experiments.

The chlorophyll content on drought stress were determined by measuring SPAD values to monitor how much the native plants maintain their healthiness and to know whether the changes in chlorophyll content of each native plants are related to withering rates (Fig. 2). Even though a decrease in SPAD values were observed in all plants, the change extents in each plant were different (Fig. 2A). The difference among the Korean native plants is shown in twelve days without watering (Fig. 2 B). Among the SPAD values of the plants in the tolerant group, relatively fewer changes were shown than the other groups. There were differences in the tolerance indexes (SPAD value on after dry/SPAD value on before dry) between the tolerant and sensitive groups (Fig. $2 \mathrm{C}$ ). While the tolerance indexes of the sensitive group were lower than $70 \%$, those of the tolerant group were higher than $90 \%$ except $C$. communis $(85.1 \%)$. Because the higher SPAD values correspond to higher chlorophyll contents, this result means that the plants in the tolerant group maintained their health on the drought condition. El-Tayeb (2006) reported that the reduction in total chlorophyll content in plantlets of Vicia faba was observed under water stress conditions. Arunyanark et al. (2008) revealed that there were

Table 1 : The lists of Korean native plant species tested for drought tolerance and their growth features in four weeks

\begin{tabular}{|c|c|c|c|c|c|c|}
\hline Plant species & Family & $\begin{array}{l}\text { Shoot length } \\
(\mathrm{cm})\end{array}$ & $\begin{array}{l}\text { Leaf number } \\
\text { (No.) }\end{array}$ & $\begin{array}{l}\text { Leaf width } \\
(\mathrm{cm})\end{array}$ & $\begin{array}{l}\text { Leaf length } \\
(\mathrm{cm})\end{array}$ & $\begin{array}{l}\text { Leaf thickness } \\
(\mathrm{mm})\end{array}$ \\
\hline Scilla scilloides & Liliaceae & $23.04 \mathrm{e}^{*}$ & $5.80^{\mathrm{m}}$ & $0.64^{h}$ & $21.02^{c}$ & $0.34^{c}$ \\
\hline Commelina communis & Commelinaceae & $28.62^{c}$ & $23.60^{\mathrm{a}}$ & $2.06^{\text {efg }}$ & $8.14^{e}$ & $0.23^{\mathrm{gh}}$ \\
\hline Hemerocallis fulva & Asphodelaceae & $29.08^{b}$ & $7.40^{k}$ & $0.62^{h}$ & $21.71^{b}$ & $0.25^{f}$ \\
\hline Bupleurum latissimum & Umbelliferae & $8.90^{n}$ & $3.40^{\circ}$ & $2.34^{\text {def }}$ & $3.08^{n}$ & $0.24^{\mathrm{fg}}$ \\
\hline Hosta plantaginea & Liliaceae & $7.16^{o p}$ & $3.60^{\circ}$ & $2.72^{\text {cde }}$ & $5.24 j^{k}$ & $0.21^{\mathrm{h}}$ \\
\hline Iris dichotoma & Iridaceae & $26.78^{d}$ & $6.00^{\mathrm{m}}$ & $0.54^{\mathrm{efg}}$ & $24.24^{\mathrm{a}}$ & $0.23^{\text {fgh }}$ \\
\hline Lysimachia barystachys & Primulaceae & $21.32^{f}$ & $\left.6.64\right|^{\prime}$ & $2.20^{\text {efg }}$ & $5.20^{i}$ & $0.91^{a}$ \\
\hline Viola mandshurica & Violaceae & $11.56^{\prime}$ & $11.20^{9}$ & $3.42^{\mathrm{bc}}$ & $5.20^{\mathrm{ik}}$ & $0.13^{\mathrm{m}}$ \\
\hline Amphicarpaea bracteata & Fabaceae & 11.84 & $10.00^{h}$ & $2.90^{\text {bcde }}$ & $4.34^{k}$ & $0.17^{\mathrm{jk}}$ \\
\hline Aeschynomene indica & Fabaceae & $29.00^{\mathrm{b}}$ & $18.00^{\mathrm{d}}$ & $1.24^{\text {gh }}$ & $3.88^{\prime}$ & $0.39^{b}$ \\
\hline Dianthus chinensis & Caryophyllaceae & $5.62^{q}$ & $19.20^{\mathrm{C}}$ & $1.45^{\text {fgh }}$ & $4.98^{\mathrm{j}}$ & $0.22^{g h}$ \\
\hline Urtica thunbergiana & Urticaceae & $13.42^{j}$ & $17.80^{d}$ & $3.94^{\mathrm{ab}}$ & $5.44^{i}$ & $0.14^{\mathrm{Im}}$ \\
\hline
\end{tabular}

${ }^{*}$ Different letters indicate significant differences Ducun's multiple range test (DMRT) at $p<0.05$ 
differences in reduction of chlorophyll content depending on the genotype of peanuts. Therefore, this result indicates that the plants in the tolerant group could maintain their healthiness on the drought condition. In addition, it can be implied that the drought tolerant plants can keep their photosynthesis even under drought conditions, or they can photosynthesize immediately since their growing conditions are improved, at least.

RWC and RWL are related to drought tolerance and these parameters have also been proposed as more important indicators of water status in plants such as wheat, potato and peanut. (Farshadfar and Ghasem, 2015; Keles et al., 2004; Soltys-Kalina et al., 2016; Arunyanark et al., 2008). These previous studies allow us to measure the water status parameters on drought stress. It was found that drought stress generally affects RWC and RWL in the Korean native plants (Fig. 3). While observing water status for 24 days, all plants in the tolerant group showed higher RWCs than $50 \%$ after 18 days of drought stress (Fig. 3 A). On the other hand, RWCs of all plants in the sensitive group and $L$. brtstachts, $V$. mandshurica and $A$. bracteata in the normal group reached $0 \%$ in the same period (Fig. 3 B-C). On the final day, the highest RWC was observed in $H$. fulva $(86.52 \%)$, followed by S. Scilloides (85.44\%), H. plantaginea (70.63\%), I. dichotoma $(70.54 \%)$, B. latissimum $(55.44 \%)$ and C. communis $(45.00 \%)$ in the tolerant group. Only RWCs of $A$. acerrifolia among the normal group showed $31.55 \%$. Similar results on water status of the native plants were shown in measurements of RWLs (Fig. 3 D-F). The RWLs of plants in the tolerant group were lower than $50 \%$ in the monitoring period. The lowest RWL on $24^{\text {th }}$ day was found in B. latissimum (30.52\%) followed by I. dichotoma (35.50\%), C. communis $(35.20 \%), H$. plantaginea (41.39), S. scilloides (42.86\%) and $H$. fulva (47.14\%) in the tolerant group. It means that no plant species totally lost their water on drought stress. However, RWLs of all plants in both normal and sensitive group, except $A$. acerifolia, reached $100 \%$ after 24 days of drought stress. The RWL of $A$. acerifolia was $65.15 \%$, which was higher than RWLs of the plant species in the tolerant group. Considering the results of RWC and RWL together, higher RWCs corresponded to lower RWLs. Therefore, the study revealed that the plants in the tolerant group can comparatively maintain their water status under drought stress because high RWC and lower RWL indicates higher potential to hold water in order to survive in drought conditions.

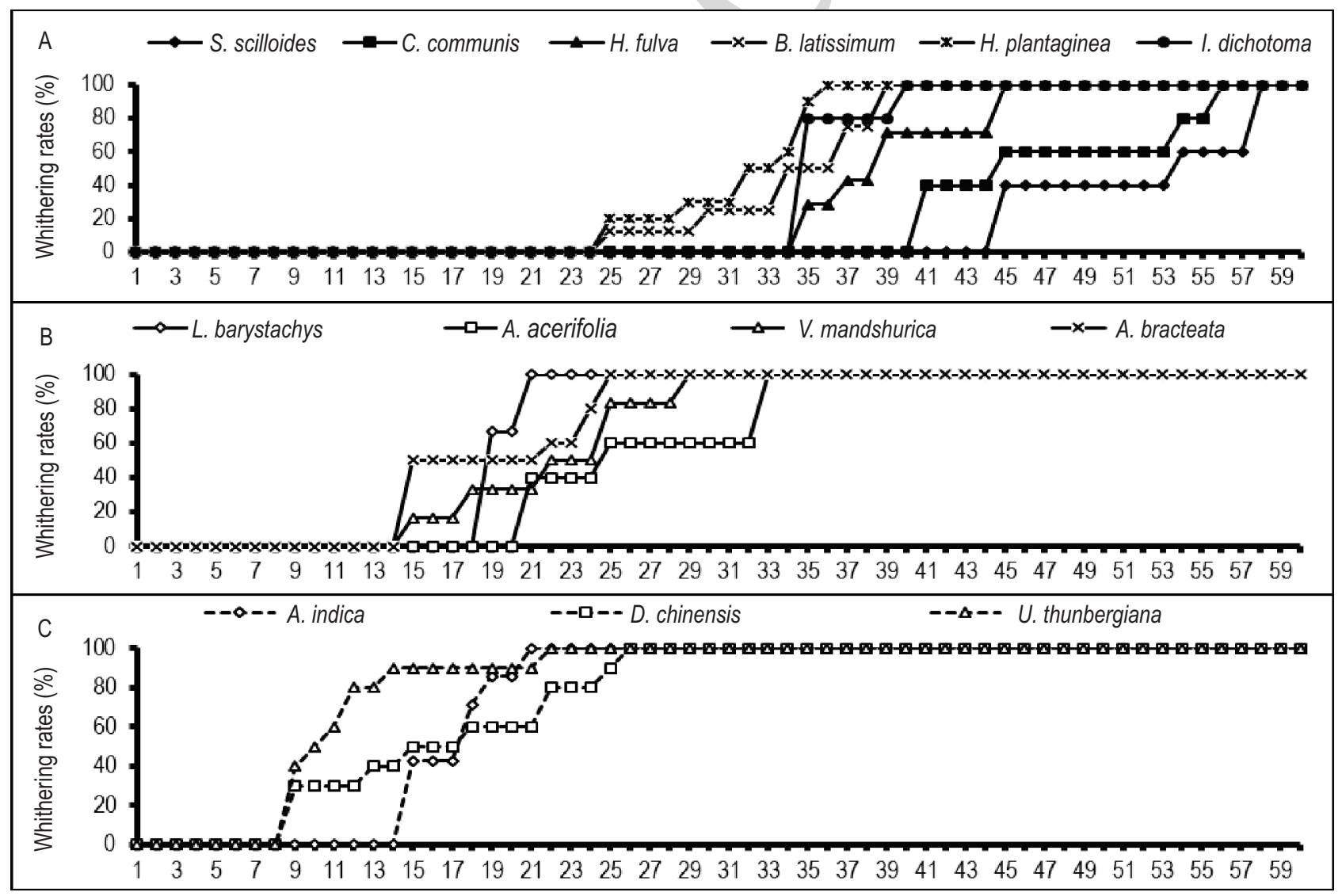

Fig. 1 : Screening drought tolerant Korean native plants. The plants of each species were exposed to drought condition by stopping irrigation and their withering rates were observed for 60 days. Each plant species were grouped into (A) tolerant; $(B)$ normal and $(C)$ sensitive groups, respectively, depending on withering rates 

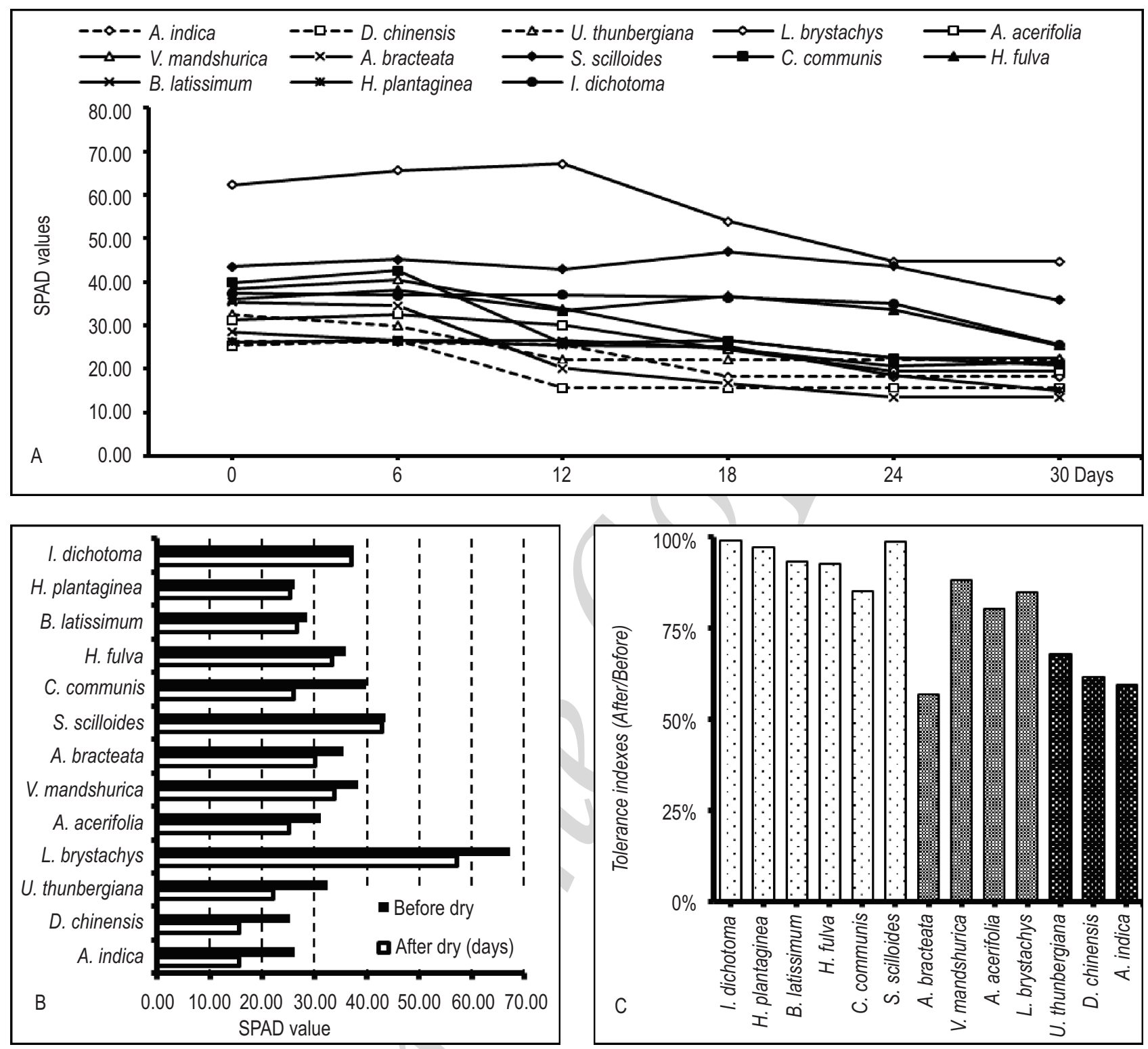

Fig. 2: Changes in chlorophyll content by drought stress treatment. (A) SPAD values of each Korean native plants on drought condition; (B) The SPAD values in 12 days and $(C)$ The tolerant indexes in 12 days. The SPAD values indicate chlorophyll contents. The SPAD values, which indicate the chlorophyll contents, were measured using SPAD device. The SPAD values were obtained from leaves of each plant species every 6 day for 30 days on drought condition

Proline has an osmolytic role for osmotic adjustment to drought stress (Levy, 1983). Irigoyen et al. (1992) have reported that the sugar contents in plant leaves can increase under drought conditions. Therefore, proline and soluble sugar contents were determined to understand how much stress by drought are accumulated in each plant species. The proline and soluble reducing sugar contents in all plant species increased with increase in drought condition (Fig. 4). However, differences in the accumulation of proline and soluble reducing sugar was observed among the groups.
The proline content was stable up to 27 days in the tolerant group (Fig. $4 \mathrm{~A}$ ). The proline content of $H$. fulva increased from $0.958 \mathrm{mg} / 0.05 \mathrm{~g}$ f.wt. on the first day to $1.069 \mathrm{mg} / 0.05 \mathrm{~g}$ f.wt. in 30 days. This change in proline content of $H$. fulva was most stable in the tolerant group. Even though the proline content of $I$. dichotoma increased from 0.973 to $3.584 \mathrm{mg} / 0.05 \mathrm{~g}$ f.wt. in 30 days, the increase was significant in 27 days. In control group, the proline content of most plants was found to accumulate from $18^{\text {th }}$ days, except in A. bracteata (Fig. 4 B). The highest increase was found in V. mandshurica on the first day. It was found that proline 

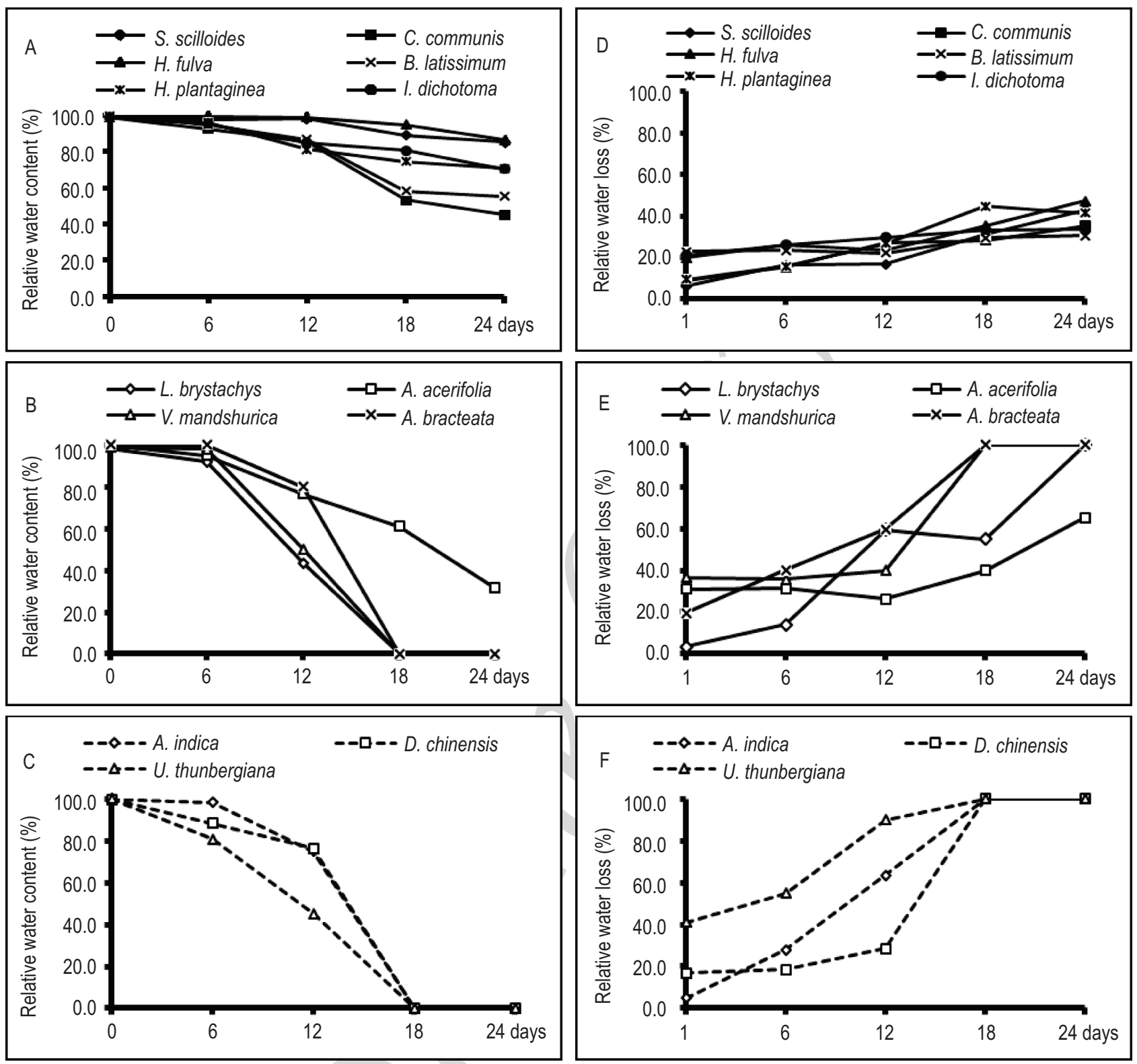

Fig. 3 : Related water content and related water loss by drought stress treatment. By collecting leaves in every 6 days on drought condition, the RWCs and RLWs were obtained. (A)-(C) RWC values and (D)-(F) RWL values

in the sensitive group began to accumulate earlier compared to the plants in the other groups (Fig. 4 C). Among all plants in the sensitive group, the proline content in $U$. thunbergiana rapidly accumulated between $6^{\text {th }}$ and $9^{\text {th }}$ day. These results indicate that the drought tolerant plants accumulated relatively low proline on drought conditions.

The soluble reducing sugar content in $B$. latissimum, $I$. dichotoma and $C$. communis in the tolerant group were stable (Fig. 4 D). Although increase in the soluble reducing sugar contents was observed in S. scilloides $\left(24^{\text {th }}\right.$ day), H. fulva $\left(24^{\text {th }}\right.$ day) and $H$. plantaginea $\left(27^{\text {th }}\right.$ day), the days were later than the other groups. In normal group, the soluble reducing sugar content of $L$. barystachys increased from the $3^{\text {rd }}$ day and was maximum on the $18^{\text {th }}$ day (Fig. 4 E). V. mandshurica, the soluble reducing sugar accumulated rapidly from $15^{\text {th }}$ day. Although slight increase was noted, the soluble reducing sugar was accumulated in $A$. acerifolia (12 days), A. bracteata (15 days) earlier than in plants of the tolerant group. In the sensitive group, the soluble reducing sugar in $A$. indica began to accumulate from $6^{\text {th }}$ day and its maximum content was shown in 15 days (Fig. 4 F). Even though they increased slightly, the soluble reducing sugar in $U$. thunbergiana (6 days) and $D$. chinensis (15 days) increased earlier than the plants in the other groups. These results indicate 

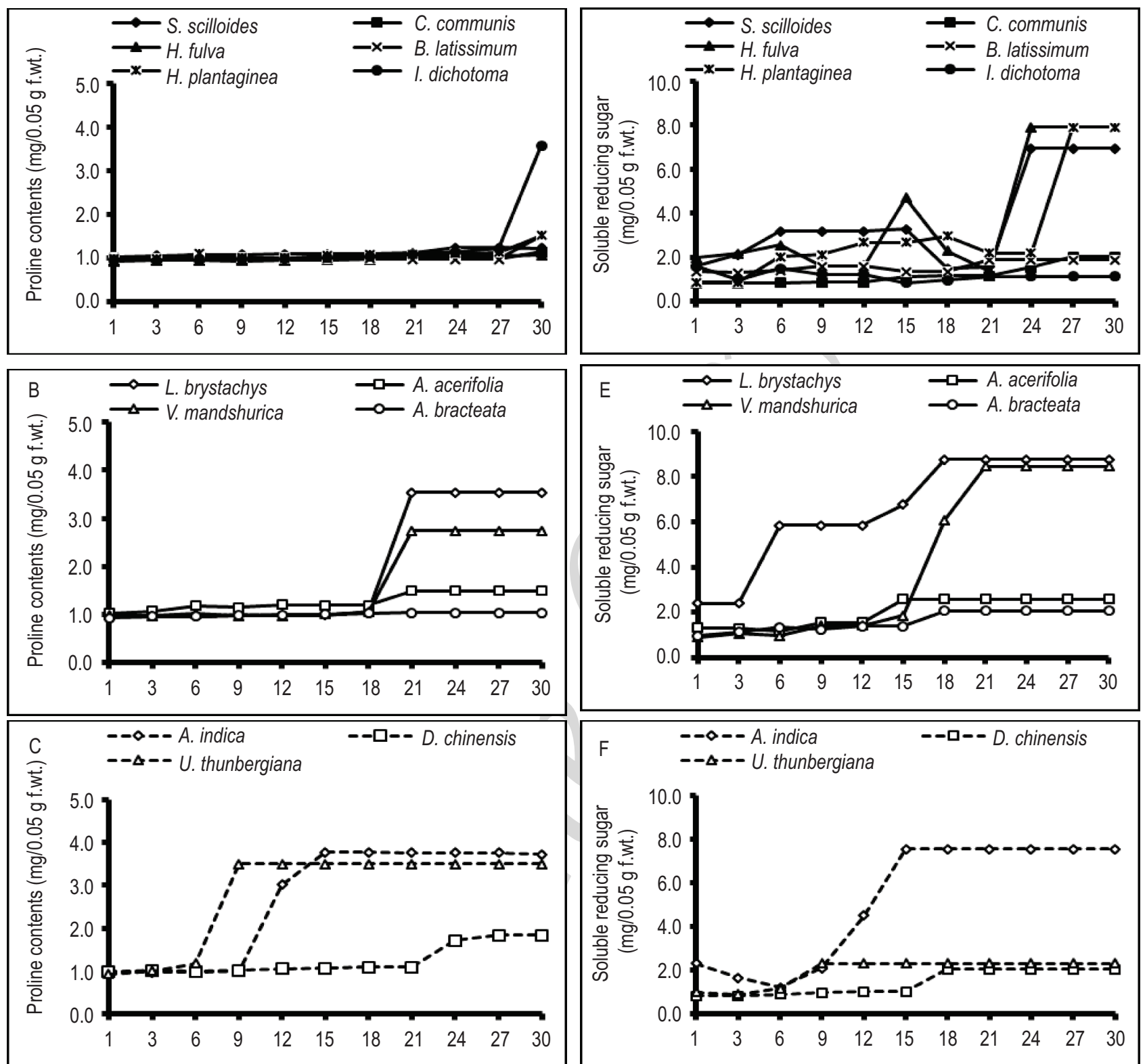

Fig. 4 : Changes in proline and reducing sugars content by drought stress treatment. The contents of proline $(A)-(C)$ and soluble reducing sugar $(E)-(F)$ on drought condition were measured to comparatively examine the extents of stress, which are accumulated in each plant species

that the soluble reducing sugar accumulated in reverse order to drought tolerant abilities of plants.

Similar reports were previously reported in bell pepper, cotton, wheat (Nath et al., 2005; Ronde et al., 2000; Hamada, 2000) and in Populus clones (Irigoyen et al., 1992; Arabzadeh, 2012; Gebre et al., 1997). Therefore, these results imply that comparatively lower stress is given to the plants in the tolerant group even though the plants are exposed to same drought conditions. The chlorophyll content, RWCs, RWLs, proline content, sugar content and the mortality of twelve species were examined using repeated measures variance analysis (Table 2). As a result, the plants can be divided into eight groups based on
SPAD values. L. barystachys, S. scilloides and I. dichotoma were grouped high SPAD values species whereas $A$. bracteata, $A$. indica and $D$. chinensis were classified into the lower SPAD values species. In the case of RWCs, eight groups were divided and, the higher RWC species were L. barystachys, S. scilloides and I. dichotoma.

The correlation analysis was performed to discover a correlation between physiological and metabolic factors. RWCs and proline contents were in a negative correlation as showing the Pearson correlation coefficient of -0.625 . This result means that plants with higher proline contents show lower RWCs. Between SPAD values and sugar contents, a positive correlation was shown 
Table 2 : Chlorophyll content, RWC, RWL, proline contents, sugar contents and mortality of twelve plant species

\begin{tabular}{|c|c|c|c|c|c|c|}
\hline Species & SPAD values & RWC & RWL & $\begin{array}{l}\text { Proline } \\
\text { content }\end{array}$ & $\begin{array}{l}\text { Soluble reducing } \\
\text { sugar content }\end{array}$ & $\begin{array}{l}\text { Withering rates } \\
(\%)\end{array}$ \\
\hline B. latissimum & $25.41 \pm 3.4^{\mathrm{fg} *}$ & $79.09 \pm 22.26^{f g}$ & $25.64 \pm 4.97^{\text {cde }}$ & $1.08 \pm 0.2^{h}$ & $1.61 \pm 0.37^{\text {ghh }}$ & $44.38 \pm 45.57^{i}$ \\
\hline C. communis & $31.5 \pm 9.85^{\mathrm{de}}$ & $76.51 \pm 24.43^{\mathrm{de}}$ & $22.92 \pm 10.19^{e}$ & $1.03 \pm 0.19^{i}$ & $1.27 \pm 0.53^{\text {gh }}$ & $22.69 \pm 34.4$ \\
\hline H. fulva & $35.59 \pm 3.32^{\mathrm{cd}}$ & $96.00 \pm 5.54^{\text {cd }}$ & $30.38 \pm 10.64^{b}$ & $1.02 \pm 0.04^{i}$ & $4.16 \pm 2.84^{\circ}$ & $36.24 \pm 44.31^{k}$ \\
\hline H. plantaginea & $24.36 \pm 4.42^{f g}$ & $84.53 \pm 12.41^{\text {fg }}$ & $27.63 \pm 14.34^{\text {bc }}$ & $1.2 \pm 0.37^{9}$ & $3.52 \pm 2.75^{d}$ & $48.72 \pm 46.42^{h}$ \\
\hline I. dichotoma & $36.55 \pm 4.65^{\circ}$ & $86.23 \pm 10.92^{\circ}$ & $28.76 \pm 5.76^{\mathrm{bc}}$ & $1.46 \pm 0.97^{\mathrm{e}}$ & $1.16 \pm 0.46^{h}$ & $41.75 \pm 48^{j}$ \\
\hline S. scilloides & $44.44 \pm 2.58^{b}$ & $93.84 \pm 5.94^{b}$ & $22.68 \pm 13.38^{\circ}$ & $1.26 \pm 0.48^{f}$ & $3.95 \pm 2.29^{\text {cd }}$ & $15.08 \pm 27.61^{\mathrm{m}}$ \\
\hline A. acerifolia & $27.6 \pm 6.27^{\mathrm{ef}}$ & $72.88 \pm 25.78^{\text {ef }}$ & $38.73 \pm 14.65^{a}$ & $1.29 \pm 0.18^{f}$ & $2.09 \pm 0.67^{e}$ & $57.33 \pm 44.47^{9}$ \\
\hline A. bracteata & $24.06 \pm 9.84^{\mathrm{fg}}$ & $56.01 \pm 47.94^{\mathrm{fg}}$ & $23.87 \pm 24.18^{\mathrm{de}}$ & $1.00 \pm 0.04$ & $1.67 \pm 0.61^{1^{\mathrm{fg} g}}$ & $69.19 \pm 41.72^{d}$ \\
\hline L. barystachys & $58.74 \pm 9.44^{\mathrm{a}}$ & $47.05 \pm 44.51^{\mathrm{a}}$ & $26.37 \pm 26.63^{\mathrm{cd}}$ & $2.05 \pm 1.27^{\circ}$ & $6.81 \pm 2.42^{\mathrm{a}}$ & $68.94 \pm 45.53^{\mathrm{e}}$ \\
\hline V. mandshurica & $32.36 \pm 8.6^{\text {cd }}$ & $49.67 \pm 45.92^{\text {cd }}$ & $22.42 \pm 19.08^{\mathrm{e}}$ & $1.72 \pm 0.88^{d}$ & $4.67 \pm 3.53^{b}$ & $64.45 \pm 43.2^{f}$ \\
\hline A. indica & $22.89 \pm 4.82^{g h}$ & $54.69 \pm 47.12^{\mathrm{gh}}$ & $19.22 \pm 25.29^{f}$ & $2.77 \pm 1.29^{b}$ & $3.81 \pm 1.32^{\text {cd }}$ & $73.07 \pm 42.01^{c}$ \\
\hline D. chinensis & $19.76 \pm 5.78^{h}$ & $52.93 \pm 45.41^{\mathrm{h}}$ & $12.77 \pm 11.6^{9}$ & $1.29 \pm 0.37^{f}$ & $1.19 \pm 0.39^{h}$ & $73.72 \pm 36.6^{b}$ \\
\hline U. thunbergiana & $25.75 \pm 6.17^{\mathrm{gg}}$ & $45.23 \pm 42.35^{\mathrm{fg}}$ & $37.22 \pm 35.59^{a}$ & $2.88 \pm 1.08^{a}$ & $1.98 \pm 0.59^{\text {ef }}$ & $82.19 \pm 34.24^{a}$ \\
\hline
\end{tabular}

*Different letters indicate significant differences Ducun's multiple range test(DMRT) at $p<0.05$

Table 3 : Correlation analysis among physiological factors for determination of dry tolerance

\begin{tabular}{|c|c|c|c|c|c|c|c|c|}
\hline & & SPAD values & RWC & RWL & $\begin{array}{l}\text { Proline } \\
\text { content }\end{array}$ & $\begin{array}{l}\text { Sugar } \\
\text { content }\end{array}$ & $\begin{array}{l}\text { Soil moisture } \\
\text { content }\end{array}$ & $\begin{array}{l}\text { Withering } \\
\text { rate }\end{array}$ \\
\hline SPAD values & $\begin{array}{l}\text { Pearson correlation } \\
\text { coefficient } \\
\text { P value }\end{array}$ & 1 & & & & & & \\
\hline \multirow[t]{2}{*}{ RWCs } & $\begin{array}{l}\text { Pearson correlation } \\
\text { coefficient }\end{array}$ & .121 & 1 & & & & & \\
\hline & $P$ value & .464 & & & & & & \\
\hline RWLs & $\begin{array}{l}\text { Pearson correlation } \\
\text { coefficient } \\
\text { P value }\end{array}$ & $\begin{array}{l}.127 \\
.440\end{array}$ & .268 & 1 & & & & \\
\hline \multirow[t]{2}{*}{$\begin{array}{l}\text { Proline } \\
\text { contents }\end{array}$} & $\begin{array}{l}\text { Pearson correlation } \\
\text { coefficient }\end{array}$ & .032 & $-.625^{* *}$ & .130 & 1 & & & \\
\hline & $P$ value & .846 & .000 & .429 & & & & \\
\hline \multirow[t]{2}{*}{$\begin{array}{l}\text { Soluble reducing } \\
\text { sugar contents }\end{array}$} & $\begin{array}{l}\text { Pearson correlation } \\
\text { coefficient }\end{array}$ & $.673^{* *}$ & -.141 & -.011 & .293 & 1 & & \\
\hline & $P$ value & .000 & .393 & .949 & .070 & & & \\
\hline \multirow[t]{2}{*}{$\begin{array}{l}\text { Withering } \\
\text { rates }\end{array}$} & $\begin{array}{l}\text { Pearson correlation } \\
\text { coefficient }\end{array}$ & & $-.866^{* *}$ & .008 & $.623^{* *}$ & .073 & & 1 \\
\hline & $P$ value & .064 & .000 & .963 & .000 & .659 & .060 & \\
\hline
\end{tabular}

*** Significant differences at $p<0.001$

Table 4 : Result of regression analysis for identifying selection factors for drought tolerant plant

\begin{tabular}{|c|c|c|c|c|c|c|c|c|}
\hline & $\begin{array}{l}\text { Independent } \\
\text { variable }\end{array}$ & $\begin{array}{l}\text { Non-standardized } \\
\text { coefficients (B) }\end{array}$ & $\begin{array}{l}\text { Standard } \\
\text { Error }\end{array}$ & $\begin{array}{l}\text { Standardized } \\
\text { coefficients (B) }\end{array}$ & $T$ & $P$ value & $\begin{array}{l}\text { Durbin- } \\
\text { Watson }\end{array}$ & $\mathbf{R}^{2}$ \\
\hline \multirow{6}{*}{ Withering rates } & Constant & $5.325 \mathrm{E}-16$ & 0.050 & - & 0.000 & 1.000 & \multirow{6}{*}{1.749} & \multirow{6}{*}{0.919} \\
\hline & SPAD values & -0.784 & 0.073 & -0.408 & $0.00-5.575$ & 0.000 & & \\
\hline & RWCs & -0.894 & 0.069 & -0.803 & -11.567 & 0.000 & & \\
\hline & RWLs & 0.352 & 0.057 & 0.120 & 2.118 & 0.042 & & \\
\hline & Proline contents & 10.633 & 0.087 & 0.328 & 3.751 & 0.001 & & \\
\hline & $\begin{array}{l}\text { Soluble reducing } \\
\text { sugar Contents }\end{array}$ & 2.089 & 0.075 & 0.174 & 2.333 & 0.026 & & \\
\hline
\end{tabular}


with 0.673 of the Pearson correlation coefficient. This result means that the higher sugar contents were proportioned with the higher chlorophyll levels in drought conditions. A positive correlation between soil moistures and RWCs were observed. The relationship between soil moisture and proline contents was in a negative correlation, and the Pearson correlation coefficient was -0.672 . Between mortality and proline contents showed a positive correlation relation with the Pearson correlation coefficient is 0.623 .

The regression analyses were performed to identify the most critical factor among physiological and metabolic factors on drought condition (Table 4). As the coefficient of regression analyses, chlorophyll content was -0.784 ; RWCs was -0.894 ; RWLs were 0.352 ; proline contents were 10.633; sugar contents were 2.089; soil moisture contents were 1.083. The orders of the factors affect to the withering rates were RWCS> SPAD values> Soil Moisture> proline contents > RWLs. These results indicated that the correlation between RWCs and proline contents were key factors for screening drought tolerant plants. It corresponds to that "Katahdin", a potato cultivar, showed higher RWC than the others and was most tolerant to drought stress (Soltys-Kalina et al., 2016). RWC, also, was a most effective way for screening drought tolerant sugarcane genotype (Silva et al., 2007). Mwadzingeni et al. (2016) have suggested measuring proline content to screen drought tolerant wheat genotype base on their observation that the positive correlation between grain yield and proline content under drought stress conditions was shown. Therefore, it can be suggested that measuring RWC and proline content under drought condition is the key ways for selection of drought tolerant plants.

In this study, the method for screening the drought tolerant plants among Korean natives was established. The drought tolerant plants commonly showed higher RWCs, decrease in chlorophyll content and later accumulation of proline and total reducing sugar than the sensitive plants under drought condition. It was shown that RWC and proline content were a key factors to screen drought tolerant plants among physiological and metabolic parameter. Therefore, the method used in this study has been able to be used to screen the drought tolerant plants, especially for wild plants. Six Korean native species (S. scilloides, C. communis, $H$. fulva, B. latissimum, $H$. plantaginea and $I$. dichotoma) were screened. It is expected that these plants can be applied to improve the adaptability of forests against climate change and to enhance efficiency for recovering devastated lands.

\section{Acknowledgment}

This research was supported by Basic Science Research Program through the National Research Foundation of Korea (NRF) funded by the Ministry of Education (2017R1D1A1 B04036320).

\section{References}

Arabzadeh, N.: The effect of drought stress on soluble carbohydrates (Sugars) in two species of Haloxylon persicum and Haloxylon aphyllum. Asian J. Plant Sci., 11, 44-51 (2012).

Arunyanark, A., S. Jogloy, C. Akkasaeng, N. Vorasoot, T. Kesmala, R.C. Nageswara Rao, G.C. Wright and A. Patanothai: Chlorophyll stability is an indicator of drought tolerance in peanut. J. Agron. Crop Sci., 194, 113-125 (2008).

Atif, O: Planning of revegetation in severe environments based on provision of vegetational shelter. Res. Bull. Coll. Exp. For., Hokkaido Univ., 45, 455-528 (1988).

Barba Jr., R.B., N.A.A. Marquez and R.P. Tablizo: Screening for Droughttolerant and low-input responsive upland rice landraces. Am. J. Plant Sci., 5, 3432-3439 (2014).

Bates, L.S., R.P. Waldren and I.D. Teare: Rapid determination of free proline for water-stress studies. Plant Soil, 39, 205-207 (1973).

Dai, A.: Drought under global warming : A review. WIREs Clim. Change, 2, 45-65(2011).

El-Tayeb, M.A.: Differential response of two Vicia faba cultivars to drought : Growth, pigments, lipid, peroxidation, organic solutes, catalase and peroxidase activity. Acta. Agron. Hung., 54, 25-37 (2006).

Farshadfar, E. and M. Ghasemi : Evaluation of drought tolerance in bread wheat using water relations and integrated selection index. J. Bio. Env. Sci., 6, 77-84 (2015)

Ganji Arjenaki, F., R. Jabbari and A. Morshedi: Evaluation of drought stress on relative water content, chlorophyll content and Mineral elements of wheat (Triticum aestivum L.) varieties. Int. J. Agri. Crop Sci., 4, 726-729A(2012).

Gebre, G.M., J.R. Brandle and M.R. Kuhns: Influence of rewatering and time of sampling on solute accumulation of two Populus deltoides clones. Tree Physiol., 17, 341-346 (1997).

Hamada, A.M.: Amelioration of drought stress by ascorbic acid, thiamine or aspirin in wheat plants. Indian J. Plant Physiol., 5, 358-364 (2000).

Helfer, F., C. Lemckert and H. Zhang: Impacts of climate change on temperature and evaporation from a large reservoir in Australia. J. Hydrol., 475, 365-378 (2012).

Irigoyen, J.J., D.W. Emerich and M. Sanchez-Diaz: Water stress induced changes in concentrations of proline and total soluble sugars in nodulated alfalfa (Medicago sativa) plants. Physiol. Plant, 84, 5560 (1992).

Jeon, G.S.: A study of improvement method and analysis of type of revegetation measures of rock slopes. J. Korean Env. Res. Reveg. Tech., 5, 22-29 (2002).

Keles, Y. and I. Oncel: Growth and solute composition in two wheat species experiencing combined influence of stress conditions russ. J. Plant Physiol., 51, 228-233 (2004).

Kidron, G.J. and R. Kronenfeld: Temperature rise severely affects pan and soil evaporation in the Negev Desert. Ecohydrol., 9, 11301138 (2016).

Kil, S.H., D.K. Lee, M.W. Cho and B.E. Yang: A study on the factors affecting vegetation cover after slope revegetation focused on a JSB method of construction. J. Korean Env. Res. Tech., 14, 127136 (2011).

Kim, D.G., H.M. Suh and N.S. Lee: Damage slope revegetation using native plant combination. J. Korea Soc. For. Eng. Tech., 6, 13-19 (2008).

Kim, S.W., K.W. Chun, K.N. Kim, M.S. Kim, M.S. Kim, S.H. Lee and J.I. Seo: Significance and future direction for designation and management of landslide-prone zones. J. For Sci., 29, 237-248 (2013).

Korea Forest Service: Introduction of landslide information system. http://sansatai.forest.go.kr. Accessed 14 June 2016 (2016).

Kumar, S., S.K. Dwivedi, S.S. Singh, S.K. Jha, S. Lekshmy, R. Elanchezhian, O.N. Singh and B.P. Bhatt : Identification of drought tolerant rice genotypes by analysing drought tolerance indices and 
morpho-physiological traits. SABRAO J. Breed Genet., 46, 217230 (2014).

Lee, T.B.: Coloured flora of Korea. Hyang-munsa Press, Inc., Seoul (2003).

Levy, D.: Water deficit enhancement of proline and amino nitrogen accumulation in potato plants and its association with susceptibility to drought. Physiol. Plant., 57, 169-173 (1983).

Longenberger, P.S., C.W. Smith, P.S. Thaxton and B.L. McMichael: Development of a screening method for drought tolerance in cotton seedlings. Crop Sci., 46, 2104-2110 (2006).

Mafakheri, A., A. Siosemardeh, B. Bahramnejad, P.C. Struik and Y. Sohrabi: Effect of drought stress on yield, proline and chlorophyll contents in three chickpea cultivars. Aust. J. Crop Sci., 4, 580-585 (2010).

Miller, G.L.: Use of dinitrosalicylic acid reagent for determination of reducing sugars. Anal. Chem., 31, 426-428 (1972).

Naser, L., V. Kourosh, K. Bahman and A. Reza: Soluble sugars and proline accumulation play a role as effective indices for drought tolerance screening in Persian walnut (Juglans regia L.) during germination. Fruits, 65, 97-112 (2010).

Nath, A.K., S. Kumari and D.R. Sharma: In vitro selection and characterization of water stress tolerant cultures of bell pepper. Indian J. Plant Physiol., 10, 14-19 (2005).

Mwadzingeni, L., H. Shimelis, S. Tesfay and T.J. Tsilo : Screening of bread wheat genotypes for drought tolerance using phenotypic and proline analyses. Front. Plant Sci., 7, 1276-1287

Park, C.M., J.W. Lee and H.J. Youn: Analysis on the quarry restoration methods in Hong Kong. J. Korean Env. Res. Tech., 2, 21-132 (2009).

Park, S.J., W.Y. Joo and S.Y. Lee: An analysis of the relationship between environmental factors and landslide hazard in Korea. The Geo. J. of Korea, 49, 267-285 (2015).

Ronde, J.A., A.V. Mescht and H.S.F. Steyn: Proline accumulation in response to drought and heat stress in cotton. African Crop Sci.
Soc., 8, 85-91 (2000).

Sakai, T., M.C. Duque, F.A.V. Cabrera, C.P. Martinez and M. Ishitani: Establishment of drought screening protocols for rice under field conditions. Acta. Agro., 59, 338-346 (2010).

Silva, M.D.A., J.L. Jifon, J.A. G.D. Silva and V. Sharma: Use of physiological parameters as fast tools to screen for drought tolerance in sugarcane. Braz. J. Plant Physiol., 19, 193-201 (2007).

Sim, S.R. and J.H. Kim: Vegetation characteristics of main herbaceous flower for ecological restoration. J. Korean Env. Res. Reveg. Tech., 9,64-71 (2006).

Soltys-Kalina, D., J. Plich, D. Strzelczyk-Żyta, J. Śliwka and W. Marczewski: The effect of drought stress on the leaf relative water content and tuber yield of a half-sib family of 'Katahdin'-derived potato cultivars. Breed Sci., 66, 328-331 (2016).

Turner, N.C., J.C. O'Toole, R.T. Cruz, E.B. Yambao, S. Ahmad, O.S. Namuco and M. Dingkuhn: Responses of seven diverse rice cultivars to water deficit. II. Osmotic adjustment, leaf elasticity, leaf extension, leaf death, stomatal conductance and photosynthesis. Field Crop Res., 13, 273-286 (1986).

Ullah, A., H. Sun, X. Yang and X. Zhang: Drought coping strategies in cotton : Increased crop per drop. Plant Biotechnol. J., 15, 271-284 (2017)

Woo, K.J. and G.S. Jeon: A study of revegetation character for environment factor of slope. J. Korean Env. Res. Reveg. Tech., 8, 47-55 (2005).

Wu, G.Q., C.M. Wang, Y.Y. Su, J.J. Zhang, R.J. Feng and N. Liang: Assessment of drought tolerance in seedlings of sugar beet (Beta vulgaris L.) cultivars using inorganic and organic solutes accumulation criteria. J. Soil Sci. Plant Nutr., 60, 565-576 (2014).

Yim, J.H., D.W. Kim and S.W. Jang: Seed germination characteristics of Korean native plants for slope restoration and revegetation. $J$. Korean Env. Res. Reveg. Tech., 2, 25-31 (1999). 